\title{
INTEGRASI TEKNIK PENDETEKSIAN OBYEK MENGGUNAKAN SENSOR PIR DENGAN KONTROL PERGERAKAN SLIDING CAMERA PADA SISTEM KEAMANAN BENGKEL
}

\author{
Deni Kurnia \\ Program Studi Teknik Mekatronika \\ Politeknik Enjinering Indorama \\ Email: deni.kurnia@pei.ac.id \\ Rizky Fitri Hidayatulloh \\ Program Studi Teknik Mekatronika \\ Politeknik Enjinering Indorama \\ Email: rizkyfitrihidayatullah@gmail.com
}

\begin{abstract}
ABSTRAK
Keamanan merupakan salah satu faktor yang diperlukan dalam setiap aktivitas manusia dan area yang ditempatinya. Salah satu area yang perlu mendapatkan perhatian keamanannya adalah gedung-gedung yang memiliki aset bernilai tinggi, seperti pabrik, bengkel, laboratorium, gudang dll. Metodologi penelitian dilakukan dengan cara merancang sistem elektronika, mekanika dan program untuk menangani sistem kemananan laboratorium yang mengintegrasikan kemampuan deteksi sensor PIR dengan sliding camera yang didesain khusus agar memiliki jangkauan yang luas. Pengontrolan gerakan kamera selain bekerja secara otomatis, juga bisa secara manual melalui web, baik melalui PC atau smartphone. Prinsip kerjanya, sistem akan memberikan peringatan melalui alarm sekaligus mengaktifkan solenoid doorlock saat itu juga untuk mengunci lab jika ada pencuri yang masuk kedalam lab. Disaat yang sama kamera dapat merekam kejadian tersebut secara realtime dan disimpan dalam bentuk data video dan gambar sebagai bukti bahwa pencuri yang bersangkutan masuk kedalam lab. Hasil penelitian memperlihatkan bahwa sistem yang dirancang dapat bekerja dengan baik sesuai dengan spesifikasi yang telah dibuat.
\end{abstract}

Kata kunci: sistem keamanan gedung, PIR sensor, web monitoring, sliding camera.

\begin{abstract}
Security is one of the necessary factors in every human activity and the area they occupy. One area of concern is the security of buildings that have high-value assets, such as factories, workshops, laboratories, warehouses etc. The methode of this research is focusing on developing electronics, mechanic and programming for security system in the laboratory that integrates capabilities of PIR sensor with a sliding camera which is specially designed to have a wide and dynamic monitoring. The function of the camera, beside it can run automatically, also can be controlled manually through the web via a PC or smartphone. The works principle are, the system will give a warning by the alarm sound and activate the solenoid doorlock to lock the lab if there are thieves who entered to lab. At the same time, camera can record the event in a real time and stored the data in video and image format. The data as a proof that the thief has entered to the lab. The result of research indicate us that system can work properly in accordance with the design that has been made.
\end{abstract}

Keywords: security of buildings system, PIR sensors, web monitoring, sliding camera.

\section{PENDAHULUAN}

Keamanan merupakan salah satu faktor yang diperlukan dalam setiap aktivitas manusia dan area yang ditempatinya. Salah satu area yang perlu mendapatkan perhatian keamanannya adalah gedung-gedung yang memiliki aset bernilai tinggi, seperti pabrik, bengkel, laboratorium, gudang dll.

Saat ini telah banyak sistem keamanan gedung yang tersedia di pasaran, seperti CCTV, alarm anti maling, dll. Namun, sistem tersebut masih memiliki keterbatasan, sehingga pengamanan masih bersifat parsial dan belum terintegrasi menjadi satu sistem keamanan yang lengkap.

Beberapa penelitian tentang sistem keamanan gedung ini pun telah dilakukan sebelumnya. Diantaranya oleh Muchlis, 2010 [1] yang melakukan penelitian sistem keamanan pintu rumah menggunakan sensor magnet berbasis mikro dan sms gateway. Penelitian selanjutnya dilakukan oleh Tri Priyono, 2011 [2] dengan melakukan perancangan sistem deteksi gerak menggunakan sinar laser dan mikrokontroler untuk sistem keamanan lab. 
Kemudian Nurkholis, 2015 melakukan penelitian tentang sistem keamanan rumah menggunakan laser pointer, LDR dan kamera digital [3]. Selanjutnya Nita Wahyu, 2015 [4] melakukan penelitian tentang sistem keamanan ruangan menggunakan sensor passive infrared dengan kontroler menggunakan AT89s51. Setahun kemudian Hariani Rika, 2016 [5] melakukan penelitian tentang keamanan pintu lab menggunakan RFID berbasis arduino uno. Pada tahun yang sama Shandy, Yan Detha, dkk, 2016 [6] menerapkan sistem penguncian pintu otomatis pada sistem kemananan smart home melalui SMS Gateway.

Dari semua penelitian tersebut, sistem keamanan yang dibangun belum ada yang mengembangkan sistem pendeteksian obyek menggunakan sensor Passive Infra Red (PIR) yang terintegrasi dengan sistem monitoring menggunakan sliding camera otomatis yang mampu merekam area pengontrolan secara dinamis.

\section{METODOLOGI PENELITIAN}

Metode penelitian yang dilakukan dalam pengembangan sistem ini dilakukan dengan cara mengidentifikasi masalah, kemudian menentukan rumusan masalah, selanjutnya menentukan tujuan serta batasan masalah penelitian.

Adapun rumusan masalah dalam penelitian ini adalah bagaimana membangun suatu sistem kemanan lab yang handal baik secara preventif maupun represif. Dari rumusan masalah tersebut dapat ditentukan tujuan penelitian yaitu untuk membangun suatu sistem keamanan lab yang handal dalam mengamankan asset lab dari tindakan pencurian yang terintegrasi dengan sistem monitoring lab secara real time. Supaya penelitian ini fokus dan terarah maka lingkup penelitian ini dibatasi pada hal-hal sebagai berikut:

a) Sistem yang dibangun pada tahap awal dilakukan di bengkel Teknik Mekatronika Politeknik Enjinering Indorama (http://pei.ac.id).

b) Untuk membangun sistem preventif, teknik pendeteksian obyek menggunakan sensor PIR (Passive Infra Red) sebagai input yang terintegrasi dengan sistem monitoring menggunakan sliding camera yang bergerak secara otomatis.

c) Selain mode otomatis, sliding camera pun dapat dikendalikan secara manual melalui handphone dan monitoring lab dapat diakses melalui browser.

d) Untuk membangun sistem represif, jika pencuri berhasil masuk kedalam lab, sistem warning yang dilakukan adalah dengan cara mengaktifkan alarm dan pintu lab akan terkunci secara otomatis.

Dari batasan masalah, maka muncul spesifikasi alat dengan skema rancangan sistem sebagai berikut (gambar 1):

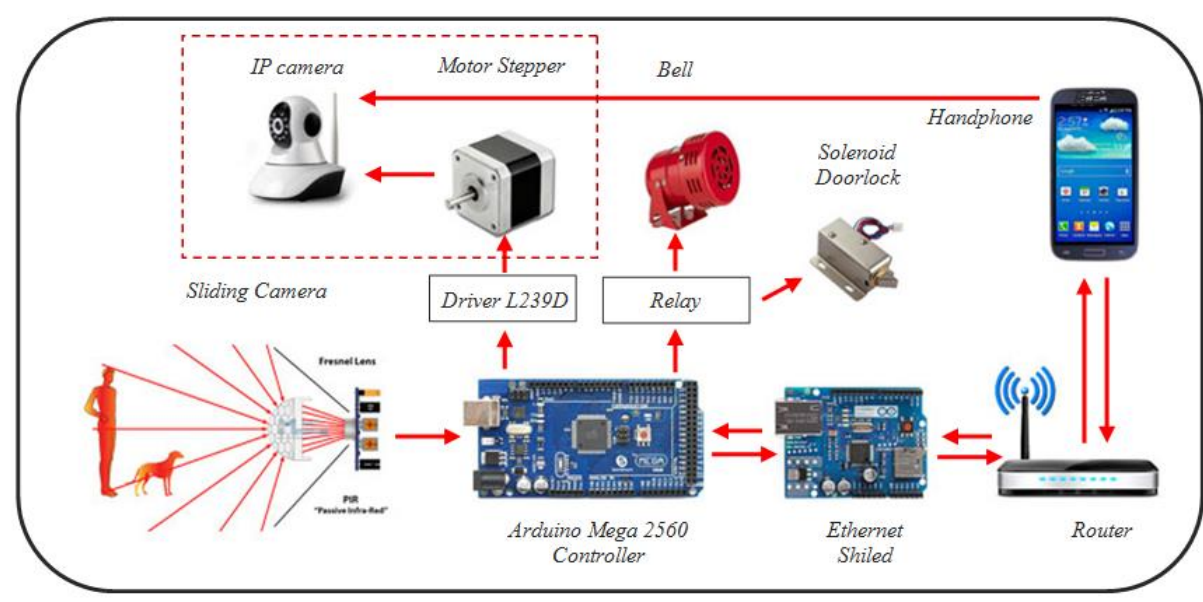

Gambar 1. Skema Rancangan Sistem

Berdasarkan skema rancangan sistem, maka dalam penelitian ini dilakukan perancangan sebagai berikut :

a) Sistem elektronik

b) Sistem mekanik

c) Program pengontrol sliding camera

\subsection{Perancangan Sistem Elektronik}

Dalam perancangan sistem elektronik, komponen input yang langsung terhubung kedalam controller adalah sensor PIR (Passive Infra Merah). Sensor PIR merupakan sensor yang bekerja dengan menangkap energi panas yang dihasilkan dari pancaran sinar infra merah pasif yang dimiliki setiap benda dengan suhu benda diatas nol mutlak, misalnya suhu tubuh manusia yang memiliki suhu tubuh di kisaran $32^{\circ} \mathrm{C}$. IR filter yang terdapat pada 
sensor PIR ini mampu menyaring panjang gelombang sinar infra merah pasif antara 8 sampai 14 mikrometer [7]. Pancaran sinar infra merah inilah yang kemudian ditangkap oleh sensor pyroelectric yang merupakan inti dari sensor PIR Akibatnya sensor pyroelectic yang terdiri dari galium nitrida, caesium nitrat dan litium tantalate menghasilkan arus listrik (gambar 2).

Dalam penelitian ini sensor PIR yang digunakan adalah tipe HC-SR501. Kebutuhan input sensor HC-SR501 menurut datasheet-nya adalah 4.5-20V DC dengan arus maksimum 50uA. Kemampuan mendeteksi sensor mulai 3-7 meter dengan delay antara 5-200 detik. Adapun sudut jangkauannya adalah $140^{\circ}$

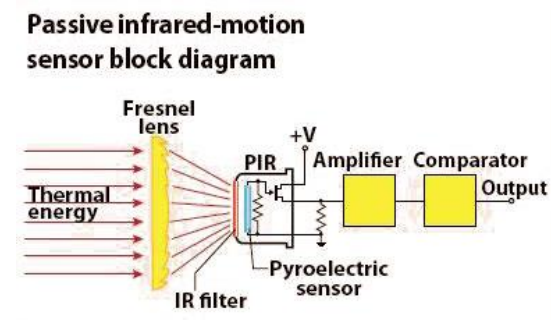

\section{Gambar 2. Blok Diagram Sensor PIR}

Controller yang dipakai untuk memproses data adalah Arduino Mega 2560. Pemilihan controller ini didasari oleh pertimbangan bahwa dengan jumlah pin I/O sebanyak 54 saluran, diharapkan mampu mengkomodasi lebih banyak device input maupun output.

Pada bagian output, komponen yang terhubung ke arduino adalah Motor drive shield L293D, Ethernet Shiled W5100 dan Modul Relay 5V.

Motor drive shield ini merupakan driver yang dirancang menggunakan IC L293D dengan desain $4 \mathrm{H}$ bridgde. Bekerja dengan level tegangan DC 4.5-36 V dengan konsumsi arus pada setiap bridge adalah 0.6 - 1 Ampere. Pentingnya digunakan driver motor dalam sistem ini adalah sebagai media pengendali maju-mundur motor stepper yang yang menopang gerak mekanik maju-mundur kamera (sliding camera). Dalam penelitian menggunakan motor stepper bipolar Nema 17 tipe hybrid dengan torsi 0.48N.m. Motor stepper ini memiliki putaran 1.8 derajat setiap langkahnya. Secara konsep prinsip kerja motor stepper adalah dengan cara memberikan pulsa-pulsa input menjadi gerakan mekanis diskrit. Kecepatan putaran rotor ditentukan oleh kecepatan perpindahan pulsa [8]. Sudut putarannya berbanding lurus dengan banyaknya pulsa yang diberikan. Jadi jika motor stepper yang digunakan memiliki putaran 1.8 derajat setiap langkahnya, artinya setiap satu pulsa input menghasilkan perputaran sejauh 1.8 derajat. Sehingga untuk memutar motor sebesar 360 derajat dibutuhkan 200 pulsa.

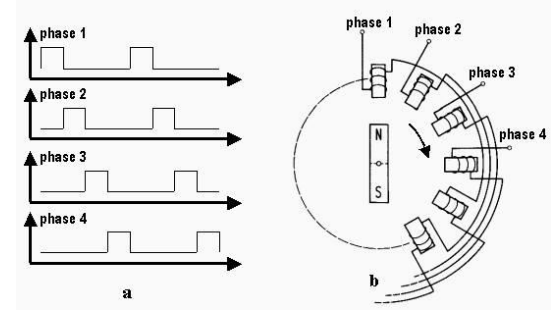

\section{Gambar 3. Grafik Pulsa dan Konstruksi Motor Stepper}

Komponen selanjutnya adalah kamera IP (IP camera). Kamera IP atau ada juga yang menyebutnya Netcam ( Network Camera ) merupakan perangkat pengambil gambar dan perekam objek yang memiliki kemampuan memproses visual dan audio serta dapat diakses komputer secara langsung, atau melalui LAN, internet, dan jaringan telepon seluler [9].

Perangkat elektronik lainnya adalah ethernet shield dengan tipe W5100. Merupakan media yang berfungsi untuk menghubungkan kontroler dengan jaringan lokal ataupun internet. Dengan menggunakan kabel UTP dengan sambungan RJ-45 tipe cross, maka shield ini dapat dihubungkan dengan router. Ethernet shield ini bekerja pada tegangan 5V DC dengan kecepatan koneksi di kisaran 10/100M.

Bagian output terakhir adalah relay dan solenoid doorlock. Relay dan solenoid doorlock merupakan komponen yang bekerja berdasarkan prinsip induksi medan elektromagnetis [10]. Prinsip kerja ini memungkinkan terjadinya gerak mekanik yang dapat digunakan untuk memutuskan atau menyambungkan arus listrik (gambar 4). 


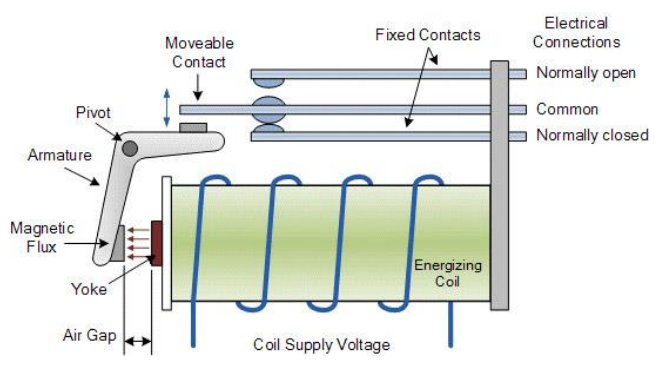

Gambar 4. Konstruksi dan Prinsip Kerja Relay

\subsection{Perancangan Sistem Mekanik}

Pada bagian perancangan mekanik, komponen penunjang gerak motor adalah rangka dan ulir. Rangka yang dibuat dipilih materialnya menggunakan besi hollow $2 \times 2 \mathrm{~cm}$ dengan metode penyambungan menggunakan welder (las). Adapun ulir yang digunakan adalah ulir berukuran $8 \mathrm{~mm}$. Dalam sistem kerja mekanik fungsi ulir disini adalah sebagai penerus daya, artinya sistem ulir digunakan untuk memindahkan suatu daya menjadi daya lain misalnya sistem ulir pada dongkrak, sistem ulir pada poros berulir (transportir) pada mesin-mesin produksi, dan sebagainya. Dengan adanya sistem ulir ini maka beban yang relatif berat dapat ditahan/diangkat dengan daya yang relatif ringan.

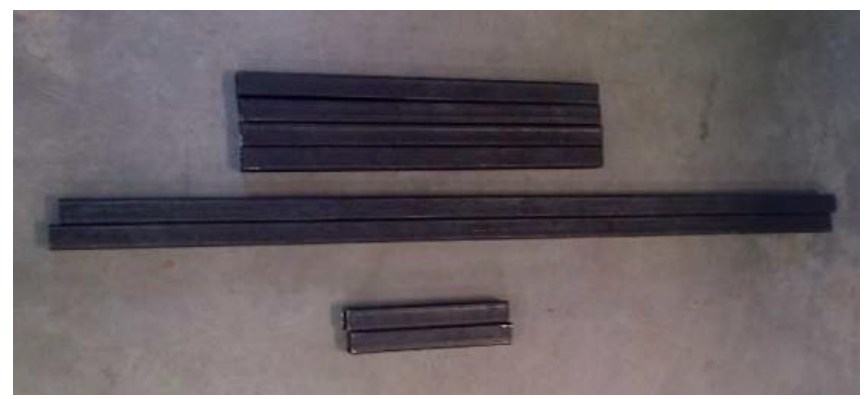

(a)

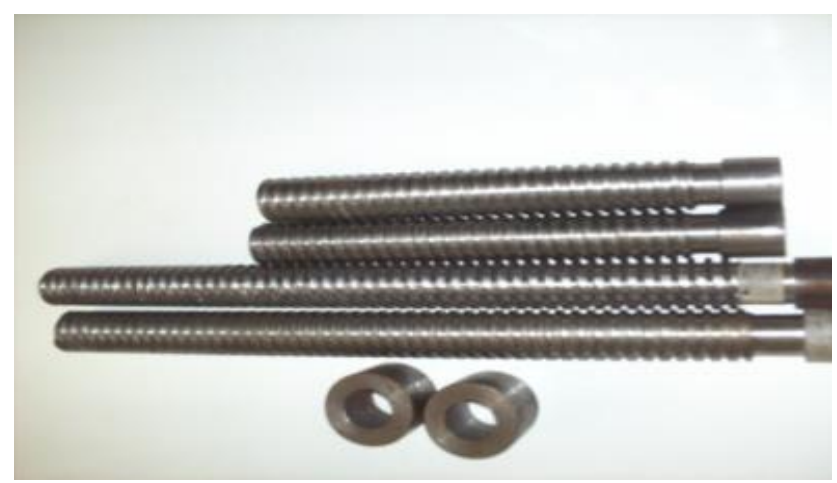

(b)

Gambar 5. Besi Hollow 2 x 2 (a) dan Ulir (b)

\subsection{Perancangan Program}

Bagian terakhir adalah perancangan program pengontrol sliding camera menggunakan IDE (Integrated Development Environment) Arduino yang terdiri dari editor program, compiler dan uploader. Secara lengkap diagram alir perancangan sistem dapat digambarkan sebagai berikut (gambar 6) : 


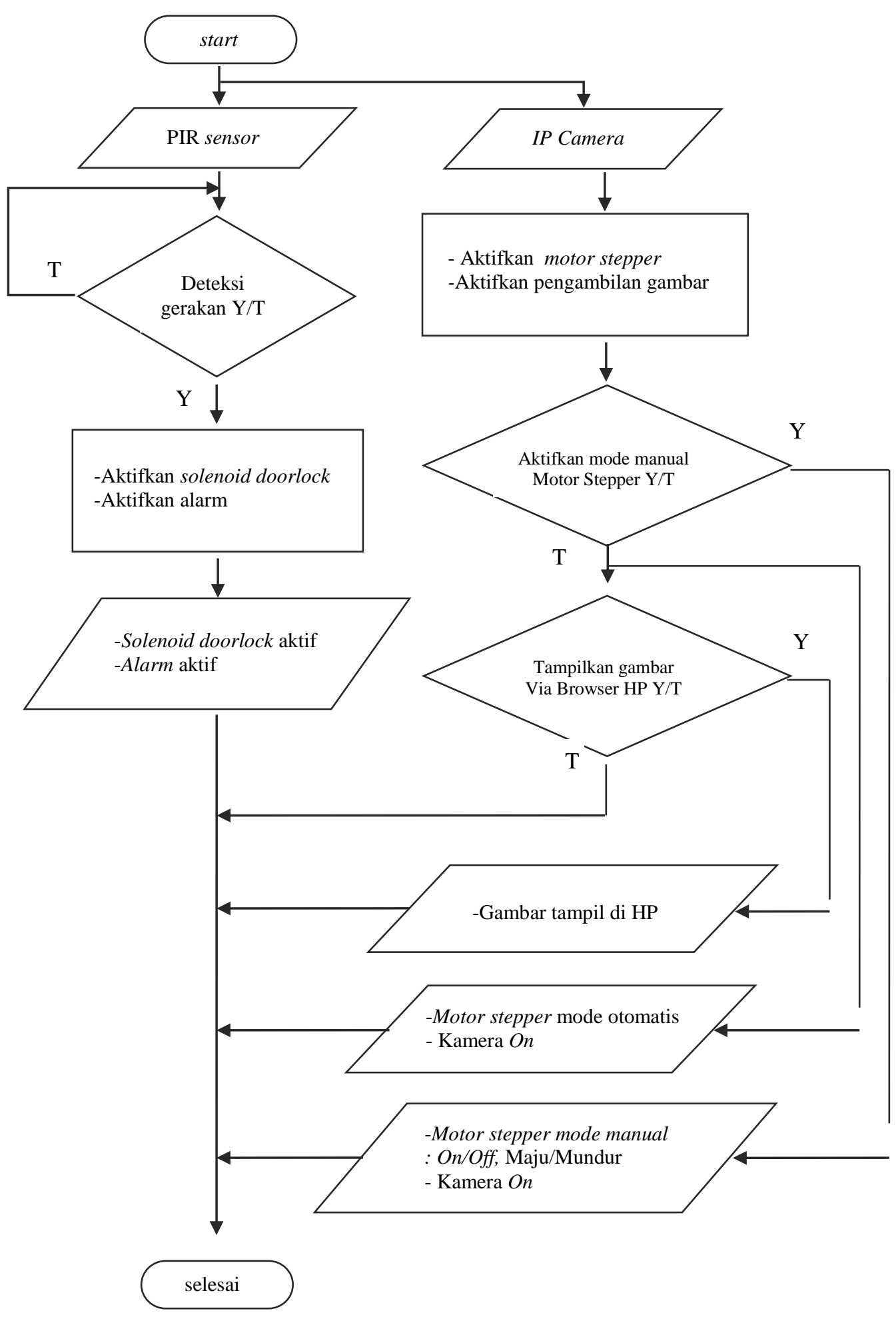

Gambar 6. Diagram Alir Perancangan Sistem

\section{HASIL PENELITIAN DAN PEMBAHASAN}

Untuk mengaktifkan sensor PIR, pada blok setup maka sensor dihubungkan ke pin digital 2 arduino, lalu dilakukan inisiasi program sebagai berikut :

int pirSensor = 2;

II... 
Langkah selanjutnya pada saat system on, matikan terlebih dahulu sensor dengan memberikan logika low dan buat variable untuk membaca status pin :

$\|$...

int sensorState = LOW;

int val $=0$;

Selanjutnya pada blok loop, dilakukan perintah ke arduino bahwa pin 2 dijadikan mode input :

pinMode(pirSensor, INPUT);

berikut:

Agar fungsi motor stepper bisa digunakan, maka dilakukan pemangilan library motor stepper sebagai

\#include <Stepper.h>

Kemudian dilakukan inisiasi pin :

int inputDriverStep1 $=5$;

int inputDriverStep2 $=6$;

int inputDriverStep3 = 7;

int inputDriverStep4 = 8;

int delay $=1$;

int timeDelay $=300000$;

$/ / \ldots$

Selanjutnya pada blok setup dibuat fungsi maju dan mundur otomatis :

$/ / \ldots$

void $\operatorname{setup}()$

$\{/ /$ inisiasi pin arduino $\}$

void maju()

\{// syntax clockwise/maju (searah putaran jarum jam)\}

void mundur()

\{// syntax counterclockwise/mundur (berlawanan putaran jarum jam)\}

Untuk mengaktifkan solenoid doorlock dan alarm maka diaktifkan pin digital 3 dan 4 sebagai berikut, dan dijadikan mode output :

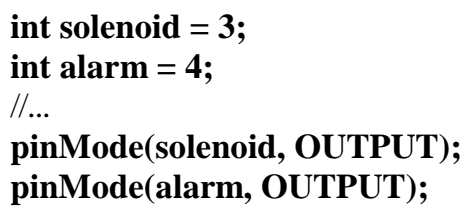

Untuk memfungsikan ethernet shield, maka dipangil library dan dilakukan setting IP Adress :

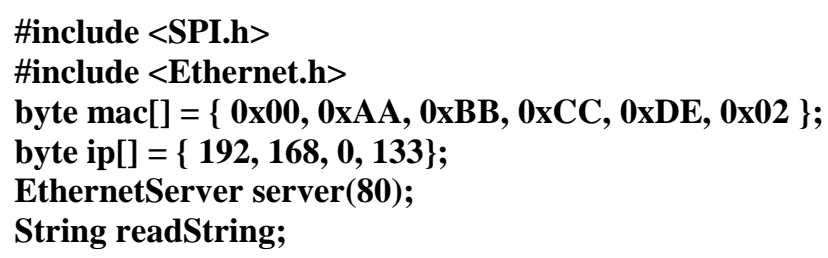

Selanjutnya untuk menggerakan motor stepper secara manual melalui IP Adress, maka diberikan pin 9 dan 10 dengan menjadikannya mode output :

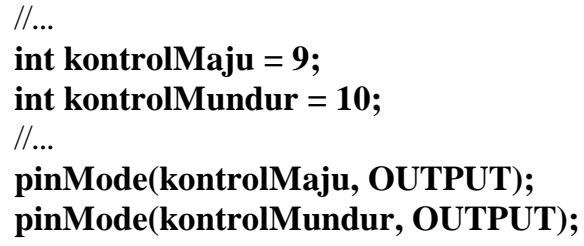

Untuk menggerakan maju dan mundur secara manual melalui browser, maka instruksi yang diperoleh controller adalah melalui string maju dan mundur dengan syntax : 


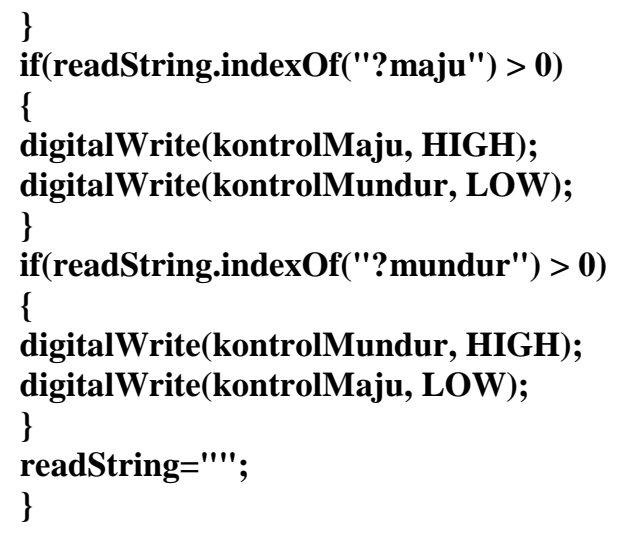

Pada bagian mekanik, slidding camera (slider) yang dibuat diharapkan mampu maju dan mundur sejauh $80 \mathrm{~cm}$ untuk meningkatkan area pemantauan. Komponen ini terdiri dari kerangka slider, dudukan stepper motor, bearing, ulir $6 \mathrm{~mm}$ dengan panjang $100 \mathrm{~cm}$. Rangka slider menggunakan bahan besi hollow 2x2 dengan ukuran: $100 \mathrm{~cm}$ x $20 \mathrm{~mm}$. Slider terbuat dari akrilik dengan ukuran $30 \mathrm{~cm}$ x $20 \mathrm{~cm}$. Tempat driver stepper motor menggunakan bahan kotak berwarna hitam dengan ukuran: $20 \mathrm{~cm}$ x $15 \mathrm{~cm}$ x $10 \mathrm{~cm}$. Roda slider menggunakan bearing dengan diameter luar $22 \mathrm{~mm}$ dan diameter dalam sebesar $8 \mathrm{~mm}$. Shaft untuk bearing menggunakan ulir dengan diameter $8 \mathrm{~mm}$ yang sudah dipotong dengan panjang $10 \mathrm{~cm}$. Gambar 7 berikut ini menampilkan rancangan dan hasil konstruksi mekanik untuk slidding camera.

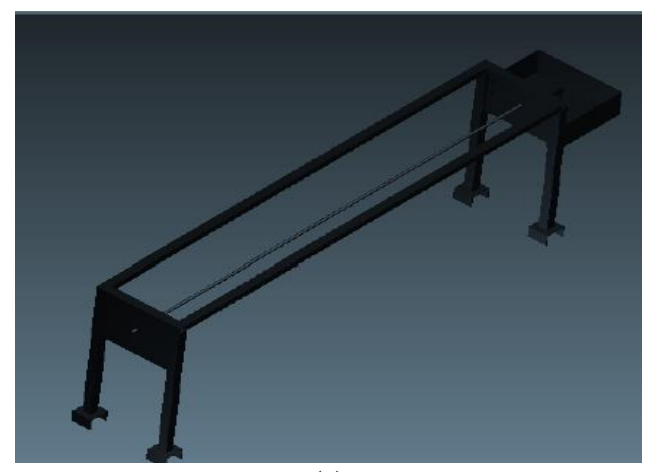

(a)

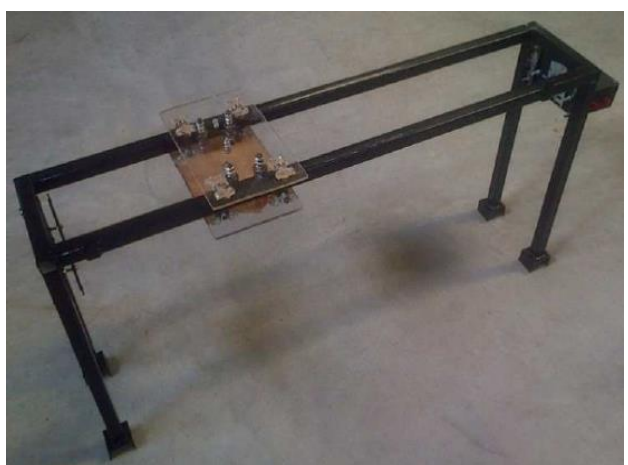

(b)

\section{Gambar 7. (a) Desain Awal Dengan Software 3D, (b) Hasil Rancangan}

Setelah semua tahap perancangan dan pembuatan selesai, selanjutnya dilakukan tahap pengujian sebagai berikut :

a) Pengujian respon sensor PIR terhadap respon alarm:

Dari tabel 1 dapat dijelaskan bahwa setelah dilakukan pengujian, jarak minimum sensor agar dapat mendeteksi obyek manusia adalah $20 \mathrm{~cm}$ dan maksimumnya adalah $300 \mathrm{~cm}$. Hal ini terbukti pada saat pengujian dilakukan, jika obyek melewati jarak $300 \mathrm{~cm}$ maka sensor sudah tidak mampu lagi mendeteksi. 
Tabel 1. Pengujian respon sensor PIR terhadap respon alarm

\begin{tabular}{ccccc}
\hline $\begin{array}{c}\text { Kondisi } \\
\text { Ruangan }\end{array}$ & $\begin{array}{c}\text { Jarak Sensor dengan } \\
\text { Manusia }(\mathbf{c m})\end{array}$ & $\begin{array}{c}\text { Tegangan Input } \\
\text { Sensor }(\text { Volt })\end{array}$ & $\begin{array}{c}\text { Keterangan } \\
\text { Alarm }\end{array}$ & $\begin{array}{c}\text { Keterangan } \\
\text { Objek }\end{array}$ \\
\hline $\begin{array}{c}\text { Ada } \\
\text { manusia } \\
\text { Ada }\end{array}$ & 20 & 4.9 & $O N$ & Terdeteksi \\
$\begin{array}{c}\text { manusia } \\
\text { Ada }\end{array}$ & 100 & 4.9 & $O N$ & Terdeteksi \\
$\begin{array}{c}\text { manusia } \\
\text { Ada } \\
\text { manusia }\end{array}$ & 200 & 4.9 & $O N$ & Terdeteksi \\
\hline
\end{tabular}

b) Pengujian sirine alarm berdasarkan variasi tegangan input :

Hasil pengujian pada tabel 2 menunjukkan bahwa sirine alarm hanya akan mulai bekerja (berbunyi) jika tegangan yang masuk bernilai 5 Volt, walaupun menghasilkan bunyi yang lemah. Namun jika bunyi alarm ingin terdengar kencang/kuat maka tegangan ideal yang masuk ke sensor adalah 12 Volt DC.

Tabel 2. Pengujian sirine alarm berdasarkan variasi tegangan input

\begin{tabular}{ccc}
\hline Tegangan (VDC) & Outpur Sirine Alarm & Kekuatan Suara \\
\hline 3.3 & OFF & Tidak Ada \\
5 & ON & Lemah \\
9 & ON & Sedang \\
12 & ON & Kuat \\
\hline
\end{tabular}

c) Pengujian gerakan sliding camera melalui smartphone:

Tabel 3 menunjukkan hasil pengujian gerakan sliding camera yang pengontrolannya dilakukan melalui smartphone. Dari tabel tersebut dapat dijelaskan bahwa untuk menempuh pergerakan maju atau mundur sejauh $80 \mathrm{~cm}$, diperlukan waktu 3.5 menit oleh sliding camera. Waktu tempuh ini ideal untuk merekam obyek di area lab, sehingga kualitas gambar sesuai dengan yang diharapkan. Respon kamera tidak menunjukkan adanya delay ketika perintah maju (forward) dan mundur (reverse) dilakukan melalui smartphone.

Tabel 3. Pengujian gerakan sliding camera melalui smartphone

\begin{tabular}{ccccc}
\hline $\begin{array}{c}\text { Arah } \\
\text { Pergerakan } \\
\text { Sliding Camera }\end{array}$ & $\begin{array}{c}\text { Perintah } \\
\text { input pada UI } \\
\text { smartphone }\end{array}$ & $\begin{array}{c}\text { Respon Sliding } \\
\text { Camera }\end{array}$ & $\begin{array}{c}\text { Waktu yang } \\
\text { dibutuhkan } \\
\text { maju/mundur }\end{array}$ & $\begin{array}{c}\text { Jarak } \\
\text { tempuh }\end{array}$ \\
\hline $\begin{array}{c}\text { Maju (menjauh } \\
\text { dari stepper } \\
\text { motor) }\end{array}$ & Forward & Bergerak & $3.5 \mathrm{Menit}$ & $80 \mathrm{~cm}$ \\
$\begin{array}{c}\text { Mundur } \\
\text { (mendekat ke } \\
\text { stepper motor) }\end{array}$ & Reverse & Bergerak & 3.5 Menit & $80 \mathrm{~cm}$ \\
\hline
\end{tabular}

d) Pengujian Hasil Perekaman IP Camera:

Pengujian IP Camera dilakukan dengan cara menguji hasil perekaman video dan image. Tabel 4 menunjukkan bahwa untuk durasi 10 menit, file video yang dihasilkan berukuran $142 \mathrm{MB}$, ukuran file meningkat menjadi $864 M B$ ketika durasi perekaman berlangsung 60 menit. Untuk menampung jumlah file yang sangat besar maka digunakan ruang penyimpanan yang berukuran besar ( 3 terabyte).

Selanjutnya untuk hasil perekaman image, ditunjukkan pada tabel 5. Ukuran file hasil capture image cukup kecil yaitu dikisaran 300-400 kb saja dengan hasil tangkapan gambar yang sangat baik pada saat sliding camera bekerja. Pengujian dilakukan melalui smartphone seperti yang ditunjukkan pada gambar 7 .

Tabel 4. Hasil perekaman video menggunakan IP camera

\begin{tabular}{ccc}
\hline No & Durasi & Ukuran File Video $(\boldsymbol{k b})$ \\
\hline 1 & 10 menit & 142363 \\
2 & 30 menit & 427089 \\
3 & 60 menit & 864178 \\
\hline
\end{tabular}


Tabel 5. Hasil perekaman gambar menggunakan IP camera

\begin{tabular}{ccc}
\hline No & File & Ukuran File Gambar $(\boldsymbol{k b})$ \\
\hline 1 & 20160721_130456.bmp & 367 \\
2 & 20160802_140158.bmp & 577 \\
3 & 20160802_140223.bmp & 382 \\
\hline
\end{tabular}

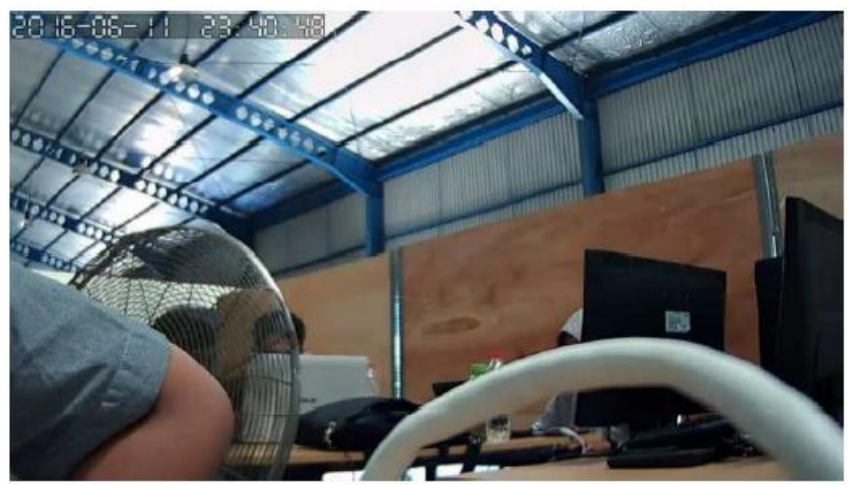

Gambar 7. Hasil Capture Sliding Camera Melalui Smartphone

\section{KESIMPULAN}

Setelah melewati tahap desain, implementasi dan evaluasi, diperoleh kesimpulan sebagai berikut :

a) Sensor bekerja dengan baik ketika menangkap gerakan manusia dengan rentang jangkauan antara 20-300 cm dan langsung memberikan sinyal HIGH ke controller untuk diproses ke tahap selanjutnya.

b) Sirine akan bekerja jika memperoleh tegangan dengan rentang antara 5-12 V dari output controller (dalam hal ini relay). Besarnya tegangan yang masuk sangat menentukan kekerasan suara sirine alarm.

c) Sliding camera dapat dikontrol secara otomatis dan manual melalui browser yang dikendalikan melalui smartphone dengan jarak maksimum maju dan mundur sejauh $80 \mathrm{~cm}$.

d) Penggunaan sistem ulir cukup efektif sebagai fungsi penyalur daya, sehingga kerja motor stepper menjadi lebih ringan dan tidak cepat panas.

e) Area pemantauan lab menjadi lebih luas dan lebar dengan adanya sistem sliding camera ini.

f) Sistem akan $O N$ dan $O F F$ secara otomatis mulai pukul $18.00 \mathrm{sd} 06.00 \mathrm{WIB}$.

g) Sistem pengamanan secara keseluruhan dapat bekerja dengan baik. Ketika sistem $O N$, maka jika ada orang masuk melalui pintu lab, sensor PIR bekerja dan alarm berbunyi. Pada saat yang sama pintu akan menutup secara otomatis dan solenoid doorlock bekerja (mengunci pintu) kemudian kamera terus merekam pergerakan dalam area jangkauannya sampai security menghentikan sistem menjadi $O F F$ dan menangkap pelaku.

\section{DAFTAR PUSTAKA}

[1] Muchlis, Muhamad. Sistem Kemanan Pintu Rumah Menggunakan Sensor Magnet Berbasis Mikrokontroler ATMEGA8 dan SMS Gateway, Universitas Pembangunan Nasional Veteran, 2010.

[2] Tri Priyono, Denis, dkk. Perancangan Sistem Deteksi Gerak Dengan Sinar Laser Menggunakan Mikrokontroler Atmega 8 Pada Laboratorium Komputer Sekolah Tinggi Keguruan Dan Ilmu Pendidikan PGRI Pacitan, Universitas Surakarta, 2011

[3] Nurkholis. Implementasi Sistem Kunci Pintu Otomatis Untuk Smart Home Menggunakan SMS Gateway, UIN Kalijaga, Jogjakarta, 2015.

[4] Wahyu, Nita. Tugas Akhir Sistem Keamanan Ruangan Menggunakan Sensor Passive Infrared (PIR) Kc7783r dengan Mikrokontroler AT89s51, Universitas Diponegoro, 2015.

[5] Hariany, Rika. Rancang Bangun Sistem Keamanan Pintu Laboratorium Kimia Menggunakan Radio Frequency Identification (RFID) Berbasis Arduino Uno, Universitas Gunadarma, 2016

[6] Shandy, Yan Detha, dkk. Implementasi Sistem Kunci Pintu Otomatis Untuk Smart Home Menggunakan SMS Gateway. Telkom University, 2016

[7] Wilson, Jon S. Sensor Technology Handbook, Elsevier.Inc. 2005.

[8] Acarnley, Paul. Stepping Motors: A Guide to Theory and Practice (Control, Robotics and Sensors), Institution of Engineering and Technology, 2007.

[9] Maulana, Asep Erlan. Instalasi Perangkat Jaringan LAN. 2015. 
[10] Platt, Charles. Make Electronics - Learning by Discovery by (2nd Edition), O'Reilly Media Inc. 2009.

[11] Kadir, Abdul. Panduan Praktis Mempelajari Aplikasi Mikrokontroler dan Pemogramannya, 2013.

[12] Solichin, Ahmad. Pemrograman Web dengan PHP dan Mysql. Universitas Budi Luhur, 2014. 